\title{
An Assessment of Environmental Awareness in Selected Areas of Jos North Local Government Area of Plateau State
}

\author{
Lawuyi T. ${ }^{1}$ and Yohanna P. ${ }^{2, *}$ \\ ${ }^{1}$ Department of Geography and Planning, Faculty of Environmental Sciences, University of Jos, Plateau State, \\ Nigeria \\ ${ }^{2}$ Department of Environmental Resources Management, Faculty of Earth and Environmental Sciences, Federal \\ University Dutsinma, Katsina State, Nigeria \\ Corresponding Author: *pyohanna@ fudutsinma.edu.ng
}

https://doi.org/10.36263/nijest.2021.02.0286

\begin{abstract}
Environmental awareness is understanding the fragility of our environment, its susceptibility to the devastating impact of human activities and the how to protect and preserve it. The research work assessed the Environmental Awareness in selected areas of Jos North Local Government area of Plateau State as its objective. The survey covered a sample population of 300 drawn from the three selected areas namely; Terminus (CBD), Faringada/University of Jos and Tudun Wada areas. The studied variables included the demographic characteristics of respondents including their ages, sex, educational attainment, family size, types of energy sources for home and industrial use, environment predispositions, knowledge of localised and general environmental facts and issues. The result showed that of the respondents, $42.86 \%$ are secondary school students, $68.22 \%$ have attained tertiary level of education, $46.72 \%$ comply with views on proper waste disposal, $38.66 \%$ dump waste into the stream, $35.37 \%$ and $27.95 \%$ of households use electricity from the mains and kerosene for cooking while $4.80 \%$ and $13.68 \%$ reported their planting and felling trees respectively. The results further showed that of the respondents, $61.57 \%$ do not ride bicycle, $99.56 \%$ use some form of renewable energy, $61.28 \%$ crave green life style while $67.62 \%$ and $1.75 \%$ rely on electricity from the mains and on solar panel as primary source of energy generation. The null hypotheses I, II and III were rejected at 0.0005 ( $p \& l t ; .05)$, degrees of freedom $=3,3$ and $1, p$-values $=48.023,190.614$ and 24.563 with respondents of tertiary level education having the highest number for knowledge of environmental awareness, age range of $36-55$ years having the highest number of environmentally friendly life style and who received enlightenment on environmental issues through informal education higher than those who received enlightenment through formal education respectively.
\end{abstract}

Keywords: Assessment, Environmental, Awareness, Energy, Climate, Population

\subsection{Introduction}

In general terms Environmental awareness means being aware of the fragility of the natural environment and consciously making choices that benefits our planet as oppose to hurting it. Some of the ways to practice environmental awareness include: using safe and non-toxic building supplies, conserving energy and water, recycling, activism, and others.

That natural catastrophes are increasing is no news, it is their scale and rate of escalation that is the real scare and for which mankind is largely to blame! The climate is changing and human activity is mainly responsible (YouGov, 2019b). However man's activities of degrading and damaging the environment started off and resulted basically from his poor awareness as a function of poor understanding, limited store of experience and eventually the daunting challenge of mitigation and remediation. The term means exactly what you expect it to: being aware of the natural environment and making choices that benefit--rather than hurt--the earth (Sullivan, 2019). 
Earth's systems are experiencing intense pressure on biological, chemical, and geological cycles, resulting from human-induced resource use and overuse at a magnitude never-before experienced (Barnosky and Hadly, 2016). Yet his abysmal awareness of the negative generational consequences of his action to the environmental seems to urge on our fool's paradise attitude. Man has failed to realise that any new factor upsets the balance of the ecosystem as a whole - the environment" (Kumar, 2012). Environmental education encompasses approaches, tools, and programs that develop and support environmentally related attitudes, values, awareness, knowledge, and skills that prepare people to take informed action on behalf of the environment (Monroe and Krasny, 2016) Environmental awareness is mostly about redressing and forestalling imbalances in global ecosystem and associated negative impacts thereof, it is about redressing the appalling levels of awareness and sheer indifference of man to his environment. Many notes that protecting and restoring the global environment will require transformative changes in human production and consumption-related behaviours, reflecting on individual choices as well as larger-scale, culturally mediated collective action (United Nations, 2019).

Although in recent times, due to marked change in our climate with attendant widespread and increasingly devastating natural disasters which has been attributed to unguarded environmental exploitation and consequent degradation, the nexus between nature calamities and environmental awareness is increasingly receiving attention and assuming a front burner global issue. Despite massive advocacy and the galvanising effort of international, regional national bodies on the push for Environmental awareness, global contemporary economic and development models appears to be staging serious and concerted fight back resulting at best in a lackadaisical commitment. Modern lifestyle that has evolved since industrial revolution with its firm foot print across centuries represents the supreme challenge to the attainment of necessary environmental awareness critical to salvaging our planet. Our "half-hearted commitment to the development of environmental awareness is largely responsible for the insatiable modern lifestyle appetite which continues to exert unprecedented and very destructive pressure on the eco-system which for many years has been showing increasing sign of inelasticity" (Hawcroft and Milfont, 2010). The picture being painted may appear too alarmist until one considers reports such as 2014 disappearance of 18 million acres ( 7.3 million hectares) of forest areas (UNEP, 2014). To be environmentally aware one must not know all; however, it requires some basic knowledge of the Earth's systems, as well as of physical and ecological systems (Hungerford,et al, 2003). Environmental education is a conservation strategy that creates such synergistic spaces, facilitating opportunities for scientists, decision-makers, community members, and other stakeholders to converge. Environmental education foregrounds local knowledge, experience, values, and practices, often in place-based settings; in this way, it encourages numerous groups, including those that may be marginalized, to interface productively with research (Toomey et al., 2017).

The generally low score on Environmental awareness and the consequent half-hearted commitment to the issues of climate change has continued to fuel our insatiable appetite for environmentally unfriendly modern lifestyle which inadvertently lead us down this treacherous part to increasing natural disasters and the prospect of ultimate planetary destruction! The task of re-educating billions of earth dwellers, re-tooling our extremely gigantic industrial complexes for transformation into green societies which must anchor on the correct environmental mentality transforming represent the consequential task of the $21^{\text {st }}$ century. There must be an ultimate U-turn which is fundamental, collective, all involving and a profoundly universal to orchestrate a shift to green living if mankind is to beat the daunting odds currently stacked against us and worsening by the day. People are pressing against planetary boundaries in ways that may permanently alter systems critical for sustaining life on Earth (Steffen et al., 2015). Our reckless dealings with environmental concerns demonstrate poor awareness of the attendant looming danger to our very existence. As the issues emerge and evolve, so does Environmental awareness which is never stagnant over time but is also dynamic and changing with the new discoveries and improved knowledge. Levels of awareness therefore differ within the context of the amount of information, personal interest and societal influence. In a separate review of climate change education, Monroe et al. (2016) identified strategies for effective climate change education, which included emphasizing a personal, local connection and undertaking action projects. Environmental problems kicks in when disequilibrium initiates and the margins continue to increase, such imbalance may be natural or usually anthropogenic. Environmental problems occur when events, either natural or human-caused, dramatically disrupt the dynamic equilibrium that exists in nature 
(e.g., carbon dioxide from human combustion of fossil fuels is released into the atmosph2aQere, movement of plate tectonics causes a tsunami, an oil tanker runs aground and releases oil into a waterway) (Marcinkowski, 2010). Some key environmental issues include population growth, use of natural and energy resources, land use, loss of biodiversity, and ecosystem deterioration at local, regional, and global levels are also needed (UNEP, 2014). Systematic and continuous re-evaluations of policies base on feedbacks and new understanding remain the habitual response of governments in pursuit of environmental awareness (Darnton, 2008). Environmental concern is the first step towards the achievement of environmental awareness (Negev et al., 2008). It is nevertheless important to recognize that awareness occurs on a continuum, and that literacy is facilitated by reflection, further learning, and additional experiences (Chawla and Cushing, 2007). Most students of the Environmental and increasingly scholars from other disciplines share the conviction that the singular most urgent threat to the wellbeing and continuation of our world as we know it hinges on environment related issues with poor societal awareness at the heart of the discus. According to Jones (2019), others believe climate change should be prioritised as part of comprehensive and radical efforts to reorganise society to mitigate and prepare for its catastrophic effects, he emphasised that climate change has reach a crisis level and tackling it must be a central focus of education. The projected global population of about 8billion by 2024 up from a meagre I billion figure of 1804 industrial revolution era further underpins the call for stronger advocacy for higher Environmental awareness as climate change induced natural disasters is here and will remain topical into the foreseeable future.

The conclusion is that the decisions to consume energy from renewable sources depend also on other parameters including societal and economic variables, on geographic and climatic conditions, and probably on "awareness" for climate change (UNFCCC, 2014). Although what man does or won't do is a function of his awareness of the consequence of his action, it is also a function of his local situation in abilities, affordability, beliefs and micro environment. It is also a function of the summation of his experiences in nature and until there is a positive change in Environmental behaviour he can't be said to be aware.

\subsection{Methodology}

\subsection{Materials}

Two main sources were used for the collection of data for this study. They are the primary and secondary sources. The primary source was through the administration of copies of a questionnaire. The secondary data were obtained through official sources such as Ministries of Environment at both Federal and State secretariats as well as desk offices at the local Government headquarters. Others include population commission, Ministry of Lands, Survey and Town Planning, Jos Metropolitan Development Board. These include archival and published materials.

\subsection{Catalyst preparation}

Prior to actual data collection, the researcher had to carry out a reconnaissance survey with a view to identify and sampling the population. The identified population was thereafter administered questionnaires and interviewed through random sampling technique.

For coverage, the data collection covered the three selected areas namely; the Central Business District, Faringada/University of Jos and TudunWada areas.

The population size of all three (3) areas under consideration is large, it is therefore not possible to cover the entire population due to the constraints of time, finance, socio-economic and human factors. It is quite important, notwithstanding, to balance the value of increased information with the cost of gathering the data.

The disparity in questionnaires allocation i.e. (100:75:75) amongst the three selected areas of Central Business District, Faringada/University of Jos and TudunWada areas respectively is meant to reflect two important considerations of population density and chance of representativeness. The central business district (CBD) or the Terminus is an area of significantly higher population density relative 
to the two other areas because of its market catchment as the city centre patronise by most other smaller markets. The researcher designed the questionnaire to capture information on the respondent's demographic, socio-economic, educational level of attainment, skills acquisition characteristics, employment status, environmental awareness level etc.

The researcher administered the copies of the questionnaires over a 3 days period commencing $1^{\text {st }}$ to $3^{\text {rd }}$ April, 2019. Considering the areas covered and the number of the copies of the questionnaires to be administered, the researcher considered it necessary to recruit seven (7) field assistants for the exercise; three (3) for Terminus area and two (2) each for Faringada/UniJos \& Tudun Wada areas respectively. A total of 250 copies of questionnaires were administered to respondents (Table 1), completed and returned or distributed but owing to some of the issues enumerated earlier, only $93.6 \%$ were successfully received back of which $91.6 \%$ were completed and returned.

Table 1: Sample size selection

\begin{tabular}{lcc}
\hline Sample area & Size & Percentage $(\%)$ \\
\hline CBD/Terminus Area & 100 & 40 \\
Faringa/Uni Jos Area & 75 & 30 \\
Tudun wada Area & 75 & 30 \\
\hline Total & 250 & 100 \\
\hline
\end{tabular}

The statistical technique, chi-square, was used to analyzed the study data. The chi-square is a nonparametric statistical technique used to determine if a distribution of observed frequencies differs from the theoretical expected frequency. The resolve to use chi-square as a statistical technique stems from the objective of the study and the amenability of the data set. The chi-square model is given as:

$\frac{\left.(O-E)^{2}\right)}{E}$

Where:

$\mathrm{O}=$ Observed frequencies

$\mathrm{E}=$ Expected frequencies

\subsection{Results and Discussions}

The demographic characteristics give information on attributes of the respondents such as sex, age. Table 2 indicates that age bracket 19-36years of the respondents were about half the entire sample population. Respondents between the age brackets 37-55years were about one third, while the balance were people of 55 years and above. This is clearly indicating that the singular majority of the respondents in the study area were youths.

Table 2: Age of the respondents

\begin{tabular}{lcc}
\hline Age categories & Frequency & Percent \\
\hline 19-36 years & 48 & 53.3 \\
37-55 years & 30 & 33.3 \\
55 years above & 12 & 13.3 \\
\hline Total & 90 & 100.0 \\
\hline
\end{tabular}

More than two third of the respondents in the study area were males while females constitute the remaining few (Table 3). This confirms that both the males and the females were involved in the survey however the wide disparity in their relative numbers does not necessarily mean that male population outstrips that of the female in the study area, rather, it suggest that males were easier to access than females during the survey exercise.

Table 3: Sex of the respondents

\begin{tabular}{lcc}
\hline Sex categories & Frequency & Percent \\
\hline Male & 80 & 88.9 \\
Female & 10 & 11.1 \\
\hline Total & 90 & 100.0 \\
\hline
\end{tabular}


The study found out that $88.9 \%$ of the respondents were males while $11.1 \%$ of the respondents were females showing clearly that there were more male than female respondents suggesting that male respondents are more amenable and receptive to research exercise than their female counterpart. This result is representative of other bodies of findings. Social and scientific researchers are typically faced with diverse reactions amongst gender (Wals 2007). Those variations particularly amongst gender is noticeable when one considers differences in education and social standing as well as age disparities notwithstanding the general conclusion above, the researcher observed that for respondents of ages 19 to 55 bracket. The study revealed that the male respondents at $88.9 \%$ scored higher than the female respondents $11.1 \%$. In the United States, the female gender was more passionate about care for the environment than the males but are not as proactive (Athman 2004).

The above finding is corroborated by the work of (Stern 2000), which compared the environmental awareness between female and male students in east Africa. The study result show that generally students had higher awareness in comparison to people outside the academic environment and more specifically showed that there is no significant difference in environmental awareness among the boys and girls students. According to Coyle (2005), evidences from many studies show that gender has no significant effect on environmental awareness. One can therefore conclude that in general, there exists no significant difference in environmental awareness amongst genders.

With respect to this study, the data generated show that less than half of the respondent $46.72 \%$ of respondents complies with the tenets of proper waste disposal. This is indeed a very serious causal factor in environmental problem. It is however interesting to note that $68.22 \%$ of the respondents are persons who have attained tertiary level of education. This finding agrees with findings of previous research. Houser (2009) stated that as people's level of awareness is raised particularly through formal education when important changes which shape lifelong disposition begin to evolve. Practical skill must however be always emphases as a critical element in the learning transfer for disposition to be effective and enduring.

The researcher also found out that secondary school respondents at modal score of 9 or $42.86 \%$ and 29 or $38.66 \%$ top the list of those who either dump waste into the stream or simply just anywhere convenient. This finding is not particularly surprising when one considers the report of many researches where it has been emphasised that environmental awareness is a progressive development as exemplified in its domain template. Chawla and Cushing (2007) said achieving environmental awareness is both progressive and reinforcing and that understanding the issues must be based on stepwise attainment of requisite knowledge and skill. The secondary school level respondents are therefore in transitory early learning and will head away from the behaviour of indiscriminate waste dumping over time.

In this study, respondent who use electricity as primary source of cooking at 81 or $35.37 \%$ of respondents tops the list for energy preference with kerosene as the second at 64 or $27.95 \%$ ahead of all the other alternatives. This result is in consonance with what obtains in many homes in Nigeria. Miller (2004) suggested that most homes in sub-Saharan Africa depend on electricity and paraffin oil for cooking when not using firewood. That government policy ought to embrace this fact to gain necessary insight critical to resolving its many issues.

This research also found out that as family size increase electricity and gas patronage appears to decrease even as kerosene and firewood usage was increasing. At family sizes of between 2-5, 5-10 and $>10$ electricity consumption decreased from $49.38 \%, 41.98 \%$ to $8.64 \%$ while firewood increased from $9.30 \%, 39.53 \%$ to $51.63 \%$ respectively. The same increasing and decreasing trends were also observed for Gas (LGP) and kerosene respectively. LaTrobe (2000) observed that as socio economic standing improves, consumption pattern seems to tilt toward elitist and cleaner energies. He maintained that without a positive change in the standard of living of the citizenry, government policy to curb deforestation will never succeed.

This research found out that while a total of 166 or $72.50 \%(51.97 \%+14.85 \%+5.68 \%)$ of the respondent confirmed that they felled trees only 136 or $59.97 \%(31.88 \% 22.71 \%+4.80 \%)$ recorded 
that they had also planted. This means $12.53 \%$ planting deficit. For the class of less than 10 trees $(0-$ $10), 31.88 \%$ and $51.97 \%$ planted and felled trees respectively and represented the most active group. Similarly, for the class of 50 trees and above $(50<), 11$ or $4.80 \%$ and $135.68 \%$ respondents planted and felled respectively as shown in Figure 1. Clearly there exists a pattern of planting deficit across board. According to Rickinson (2001), deforestation remains a major environmental challenge in developing countries where planting deficit is ever widening. The realisation and acceptance that poverty and ignorance will continue to sustain this situation for a very long time is an important reminder to efforts to resolve it. Deforestation is a major global concern, therefore a widening deficit of $12.53 \%$ demand serious concern.

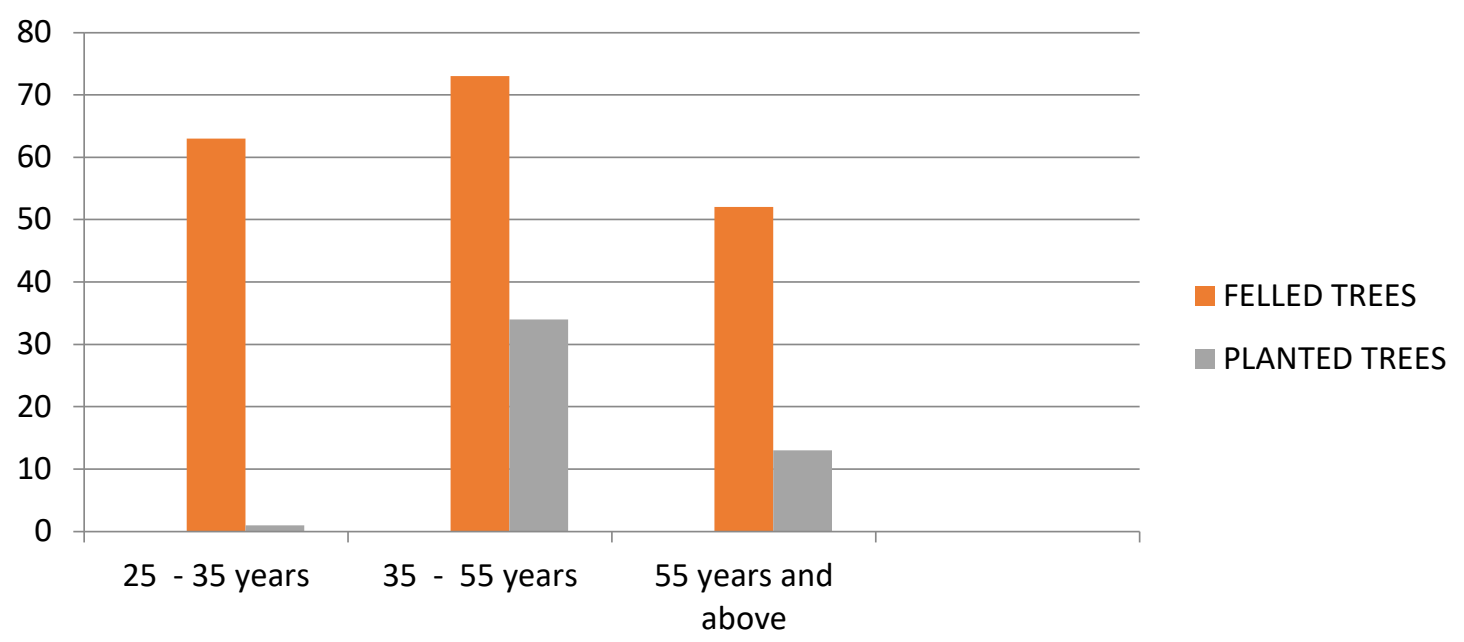

Figure 1: Histogram showing how respondents who planted trees compared with those who felled trees.

The results show that $61.57 \%$ of respondents do not ride a bicycle while $54.15 \%$ respondents also do not engage in discriminating against bio non-degradable products (Figure 2). This indicate serious gap in important environmental attitude. Riding bicycle and discrimination against patronage of bio nondegradable products are key elements in the mitigation of urban environmental pollution

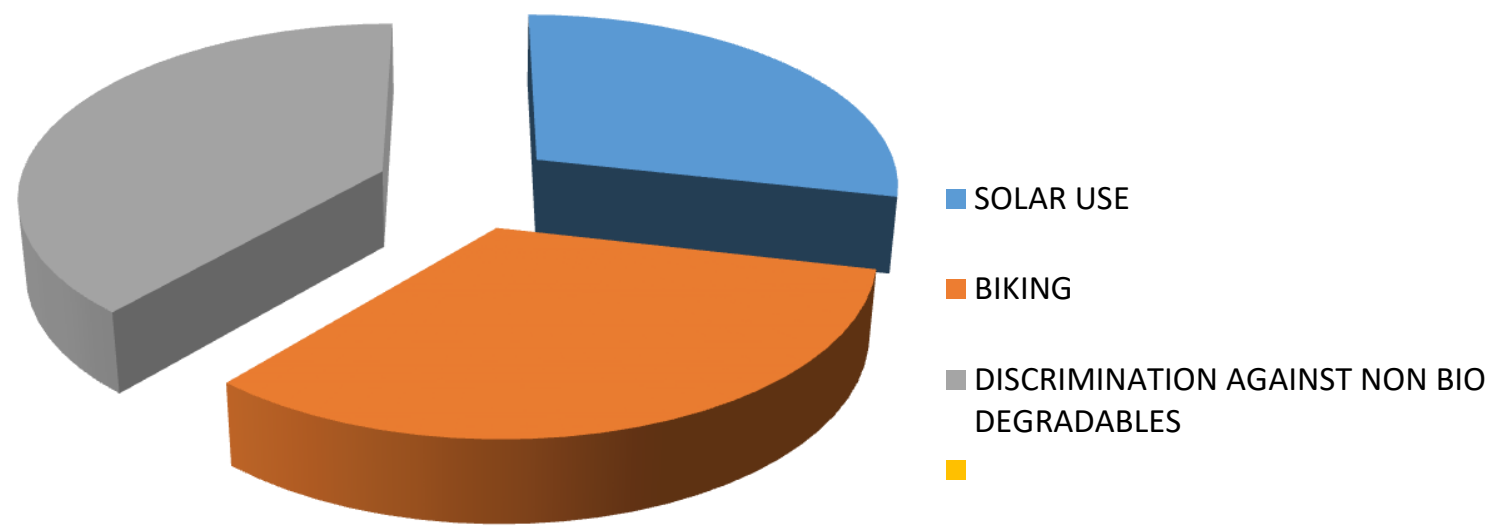

Figure 2: Pie chart showing green lifestyle preference

However, the research also indicated that 228 or $99.56 \%$ of respondents also regularly or occasionally use solar energy while overall, 140 or $61.28 \%$ of the respondents generally prefer green life style as against the $38.72 \%$ who do not as shown in Figure 3. This result compares with similar finding in other settings. Hungerford (2003), environmental awareness and corresponding attitudes are dynamic 
and expectedly evolving. The varieties of situations are a function of many varying and complex values and operations.

The results also revealed that 148 or $67.62 \%$ of the respondents confirm their use of electricity as the primary source of energy in their business place of work. However, the power resource least used for business is solar energy at 4 or $1.75 \%$ of respondent. It is evident therefore that all other energy sources combine does not equal half of electricity consumption from the mains. The finding also indicated that next to electricity from the mains, 52 or $22.70 \%$ of the respondents use either of petrol, diesel or kerosene as primary energy sources for their business or at place of work as shown in figure 4. Wagner, (2003), electricity may qualify to be termed the most widely used industrial energy in subSaharan Africa, but this is not entirely true because most of the time petrol or diesel using plants are never silent for long.

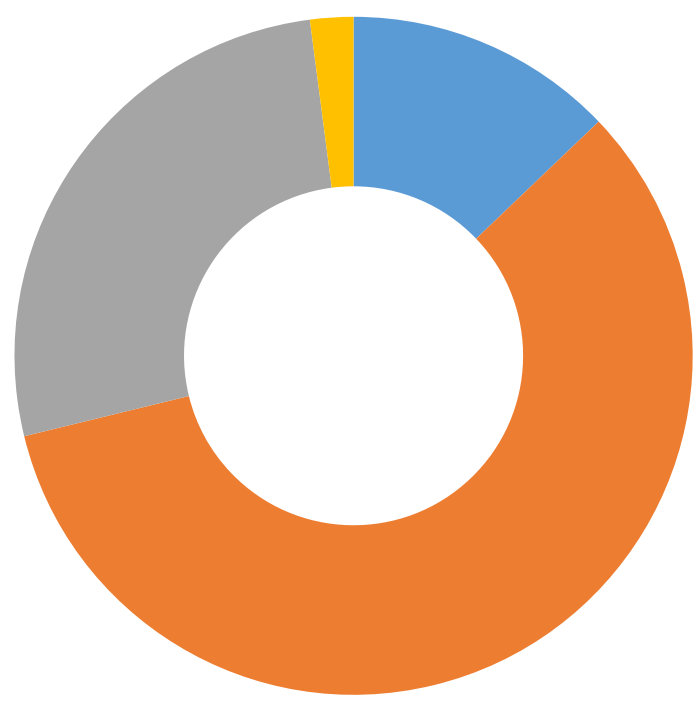

- COAL/FIREWOOD

$\because$ ELECTRICITY

DIESEL/PETROL/KEROSENE

SOLAR

Figure 3: Doughnut chart showing relative energy sources used by businesses

The result show that the highest number of respondents at $64.62 \%$ or 148 entries use electricity from the mains as the power source for their businesses as oppose to solar energy which is the least entry at $1.75 \%$ or 4 respondents. According to Dillman et al. (2002), reasons for the preference for electricity as a primary sources of energy by industries in developing countries is not far fetch; poorly managed refineries, financial licks etc. has continue to render the cost of products delivery very prohibitive. The unreliability of supply and hyper demand of petroleum products like petrol and diesel are common phenomenon which combines to create this unfavourable situation. The dismal showing of a carbon neutral energy source like solar at $1.75 \%$ as against the carbon based sources such as coal, kerosene, diesel, firewood and charcoal at $33.36 \%$ demonstrates the pressing awareness gap.

\subsection{Hypothesis result}

\section{Hypotheses I:}

$\mathrm{H}_{1}$ : There is significant difference between levels of education and knowledge of measured environmental awareness.

$\mathrm{H}_{0 \text { : }}$ There is no significant difference between levels of education and knowledge of measured environmental awareness.

This was tested and the null hypotheses rejected at $0.0005(\mathrm{p}<0.05)$, Degree of freedom $=3$, $\mathrm{p}$-value $=48.023$ with respondents of tertiary level of education having the highest score for knowledge of measured environment awareness. The alternative hypothesis was therefore accepted

\section{Hypotheses II:}

$\mathrm{H}_{1}$ : There is a significant difference between age and environmental friendly life style.

$\mathrm{H}_{0}$ : There is no significant difference between age and environmental friendly life style. 
This was tested and the null hypotheses rejected at $0.0005(\mathrm{p}<0.05)$, Degree of freedom $=3$, p-value $=190.614$ with respondents within the age range of $36-55$ years having the highest number of environmental friendly life style. The null hypothesis was therefore rejected and the alternative hypotheses accepted.

\section{Hypotheses III:}

$\mathrm{H}_{1}$ : There is significant difference between people who receive enlightenment on environment issues through formal and informal education.

$\mathrm{H}_{0}$ : There is significant no difference between people who receive enlightenment on environment issues through formal and informal education.

This was tested and the null hypotheses rejected at $0.0005(\mathrm{p}<0.05)$, Degree of freedom $=1, \mathrm{p}$-value $=24.563$ with respondents who receive enlightenment on environment issues through informal education higher than those who receive enlightenment through formal education. The null hypothesis was therefore rejected and the alternate hypothesis accepted.

\subsection{Conclusions}

This study examined the Environmental awareness in selected areas in Jos North Local Government area, Plateau State. The findings shows that relatively few percentage of the respondents dump waste into streams, rely on use electricity for cooking, use kerosene, planted and felled trees. The results show that most of the respondents do not ride a bicycle however, the research also indicated that most the respondents use some form of solar energy while majority of the respondent prefer green life style. The results also revealed that more than half of the respondents use electricity as the primary source of energy and very negligible number of respondents rely on the use of solar energy as primary source of power. Respondents who have attained tertiary level of education scored the highest number for environmental awareness level while those within the age range of $36-55$ years scored the highest number for environmental friendly life style. Also respondents who received enlightenment on environmental issues through informal education are significantly higher than those who received enlightenment through formal education.

Based on the conclusion, the following recommendations were put forward:

i. The Government need to articulate policies designed to amplify awareness of the established links between the use of nonrenewable energy and climate change.

ii. Educational tools in the form of Environmental courses should be mandated in all primary, secondary and in tertiary institutions to achieve and deepen environmental literacy.

iii. Government should proactively creation condition which intensifies and deepen level of Environmental awareness through deliberate incentive like targeted rebates and subsidies while discouraging eco-degrading activities through taxes and penalties.

iv. People should be encourage to set yearly practical and achievable targets for mitigating, remediating and reversing environmental damages through a combination of tree planting, consumption preferences, waste disposal best practices, green lifestyle etc.

v. Government at all levels should actively engage with relevant non-Governmental organizations for sustained campaign on environmental awareness and for eco-friendly style enlightenment.

\section{References}

Athman, J. (2004). The effects of environment-based education on students' critical thinking and achievement motivation. (Doctoral dissertation, University of Florida, 2003). Available in Dissertation Abstracts International: Section A. Social Sciences and Education, 64 (9), 3237.

Barnosky and Hadly, (2016). Tipping Point for Planet Earth: How Close Are We to the Edge? Thomas Dunne Books, New York.

Chawla, L. and Cushing D. (2007). Education for strategic environmental behaviour. Environmental Education Research, 13(4), pp. 437-452. 
Coyle, K. (2005). Environmental literacy in America: What ten years of NEETF/Roper research and related studies say about environmental literacy in the U.S. Washington, DC: The National Environmental Education and Training Foundation.

Darnton, A. (2008). Reference report: An overview of behaviour change models and their uses. London: University of Westminster.

Dillman, D. A., Eltinge, J. L., Groves, R. M. and Little, R. J. A. (2002). Survey nonresponse in design, data collection, and analysis. New York: John Wiley \& Sons

Hawcroft, I. and Milfont, T. (2010). The use and abuse of the New Environmental; Paradigm scale over the last 30 years: A meta-analysis. Journal of Environmental Psychology, 30(2), pp. 143-158.

Houser, N. (2009). Ecological democracy: An environmental approach to citizenship education. Theory \& Research in Social Education, 37 (2), 192-214.

Hungerford,H., Volk, T., Ramsey, J., Litherland, R., \& Peyton, R. (2003). Investigating and evaluating environmental issues and actions. Champaign, IL: Stipes Publishing, L.L.C.

Jones, T. (2019). Tackling the climate crisis must be a central focus of education. Times Educational Supplement.

LaTrobe, H., \&Acon, T. (2000). A modified NEP/DSP environmental attitudes scale. The Journal of Environmental Education, 32 (1), 12-20.

Marcinkowski, T. (2010). Contemporary challenges and opportunities in environmental studies: Where are we headed and what deserves our attention? The Journal of Environmental Education, 41(1), pp. 34-54.

Monroe, M. C. and Krasny, M. E. (2016). Across the Spectrum: Resources for Environmental Education (3rd Ed.). North American Association for Environmental Education, Washington, DC

Miller, G. (2004). Living in the environment (13th ed.). Pacific Grove, CA: Brooks/Cole Thomson Learning.

Negev, M., Sagy, G., Garb, Y., Salzberg, A. and Tal, A. (2008). Evaluating the environmental literacy of Israeli elementary and high school students. The Journal of Environmental Education, 39 (2), pp. 3-20.

Kumar, S. (2012); Essay on the Need of Public Awareness for Environmental Studies. http://www.preservearticles.com/2012042331067/essay-on-the-need-of-public-awarenes forenvironmental-studies.html.

Stern, P. (2000). Toward a coherent theory of environmentally significant behaviour. The Journal of Social Issues, 56 (3), 407.

Sullivan.N,(2019)Environmental-awareness-definition-history-importance https://study.com/academy/lesson.html

Rickinson, M. (2001). Special Issue: Learners and learning in environmental education: A critical review of the evidence. Environmental Education Research, 7 (3), 208-320.

Toomey A.H., Knight A.T. and Barlow, J. (2017) Navigating the space between research and implementation in conservation. Conserv. Lett., pp. 619-625. 
United Nations Climate Change Conference, (2014) The Warsaw Framework for REDD-Plus (Decisions 9/CP.19, 10/CP.19, 11/CP.19, 12/CP.19, 13/CP.19. 14/CP.19 and 15/CP.19). http://unfccc.int/resource/docs/2013/cop19/eng/10a01.pdf

United Nations Environment Programme (2014), Driving a Green Economy Through Public Finance and Fiscal Policy Reform. http://www.unep.org/greeneconomy/portals/30/docs/DrivingGreenEconomy.pdf

UN Environment. Cambridge University Press; Cambridge, UK: 2019. Global environment outlookGEO-6: Healthy planet, healthy people. Available at: https://www.ncbi.nlm.nih.gov/pmc/articles/PMC7348615/\#bib93 [Accessed 15 Oct.2012]

Wagner, M., (2003) "Does it pay to be eco-efficient in the European energy supply industry?" Zeitschrift für Energiewirtschaft 27(4):309-318.

Wals, A. (2007). Social learning towards a sustainable world. Wageningen, The Netherlands: Wageningen Academic Publishers.

YouGov (2019) "Climate Change Protesters Have Been Carrying out Their Aim." Available at: https://yougov.co.uk/topics/science/survey-results/daily/2019/10/15/470b6/1 [Accessed 28Oct.2021]. 